PALABRAS DE AGRADECIMIENTO DEL DR. VÍCTOR ML. SÁNCHEZ CORRALES, CON OCASIÓN DEL HOMENAJE QUE SE LE OFRECIERA EN LA SEGUNDA SEMANA DE LA DIVERSIDAD LINGÜÍSTICA DE COSTA RICA

Víctor Ml. Sánchez Corrales

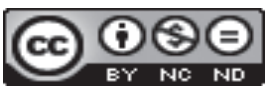

Esta obra está bajo una licencia Creative Commons

Reconocimiento-No Comercial-Sin Obra Derivada 



\title{
PALABRAS DE AGRADECIMIENTO DEL DR. VÍCTOR ML. SÁNCHEZ CORRALES, CON OCASIÓN DEL HOMENAJE QUE SE LE OFRECIERA EN LA SEGUNDA SEMANA DE LA DIVERSIDAD LINGÜÍSTICA DE COSTA RICA
}

\section{WORDS OF GRATITUDE BY DR. VÍCTOR M. SÁNCHEZ CORRALES, ON OCCASION OF THE TRIBUTE OFFERED DURING THE SECOND WEEK OF LANGUAGE DIVERSITY IN COSTA RICA}

\author{
Víctor Ml. Sánchez Corrales
}

Señor Dr. Carlos Villalobos Villalobos, Director de la Escuela de Filología, Linguiística y Literatura

Señora Dra. Carla Jara Murillo, Directora del Departamento de Lingüística

Señor Dr. Carlos Sánchez Avendaño, Organizador de la Segunda Semana de la Diversidad Lingüística

Compañeros profesores de la Escuela, queridos estudiantes, amigos todos:

Se cumplen hoy tres años, tres meses y tres días de haberme acogido a mi jubilación, tres- tres- tres, número de gran pertinencia en nuestra cultura, cuyo simbolismo se remonta a la Biblia, y ustedes, en esta fecha marcada con el tres-tres-tres, me obsequian con esta generosa dedicatoria. La recibo con tres sentimientos: agradecimiento, humildad y júbilo.

Agradecimiento a mis padres por haber invertido en mi formación; nunca podré olvidar su esfuerzo económico para que pudiera cursar el sexto grado en una escuelita que distaba de casa el equivalente a una hora a caballo, en aquel pueblito, Los Reyes, del entonces lejano Pérez Zeledón. De lunes a sábado me quedaba a dormir y a comer, dicho hoy más formalmente, me hospedaba en la casa del maestro, por cuyo concepto pagaban treinta colones al mes (tres veces diez), reunidos de la cosecha de café. Al escribir estas palabras descubro por qué tengo tres matitas de café sembradas en casa...

Dr. Víctor Ml.Sánchez Corrales. Universidad de Costa Rica. Doctor en lingüística. Profesor emérito de la Escuela de Filología, Lingüística y Literatura. Costa Rica.

Correo electrónico: victor.sanchez@ucr.ac.cr

Recepción: 20- 02- 2014

Aceptación: 18- 03- 2014 
Agradecimiento a una Costa Rica solidaria en la que me ha correspondido vivir porque, en el conglomerado de las naciones más cercanas, ella como ninguna ha invertido en la educación de sus hijos: más escuelas, más colegios, sin descuidar en ese entonces la calidad profesional de los formadores, cuya responsabilidad recaía en las escuelas normales, en el Instituto de Formación Profesional del Magisterio y en la Universidad de Costa Rica. En esa Costa Rica solidaria había una clara conciencia sobre cuál era la única opción de desarrollo de la persona hacia una vida en comunidad verdaderamente plena, una vida que, más allá de la sola satisfacción de sus necesidades básicas, le permitiera a la persona asumir un rol activo, fecundo, propositivo y con pertinencia en todos los aspectos de su actividad familiar y comunitaria; esa única opción de desarrollo humano era la educación. Esta sociedad fraterna se cristaliza en la Universidad de Costa Rica, institución que me becó tanto en mi carrera de grado como durante los estudios de doctorado. Aprovecho esta oportunidad para agradecer también a esta casa de educación superior y cultura por medio de las personas que en esta ocasión ostentan cargos docente-administrativos y nos honran con su presencia en este acto protocolario.

Y, por supuesto, agradecimiento también a USTEDES, escrito con mayúscula, por este acto generoso y noble al obsequiarme con esta Segunda Semana de la Diversidad Lingüística; porque ustedes, no puedo ocultarlo, me han obsequiado con lo más humano del ser humano: la palabra que escudriña, con pasión y perseverancia, los intrincados vericuetos de textos lingüísticos, literarios y culturales de esta Costa Rica multilingüe, pluriétnica y multicultural; me obsequian con la palabra que, entretejida por los humanos hablantes, atesora su experiencia comunitaria de vida, definiéndolos ante el mundo como exponentes del "zoon logicón”. Al respecto, es oportuno citar al maestro Coşeriu: "El lenguaje puede definirse como el primer aparecer -como nacimiento- de lo humano y como apertura de las posibilidades propias del hombre. En efecto, el lenguaje es el primer presentarse de la conciencia humana como tal (puesto que no hay conciencia vacía y puesto que sólo mediante su objetivación la conciencia se deslinda a sí misma, al reconocerse como otra cosa que «el mundo») y, en el mismo acto, la primera aprehensión del mundo por parte del hombre. Como actividad libre, es, asimismo, el primer fenómeno de la libertad del hombre. Como actividad intersubjetiva, es la base de lo social y la forma fundamental de la historicidad del hombre, por lo cual es también instrumento de comunicación e instrumento de la vida práctica. Y como aprehensión del mundo, es supuesto y condición de la interpretación del mundo, o sea, del pensamiento en todas sus formas, $\mathrm{y}$, con ello, de la búsqueda de la verdad, que es prerrogativa esencial del hombre en el universo" (Coşeriu, 1977, p. 64). ¡No tengo palabras, apreciados compañeros y amigos, para agradecer este obsequio de la palabra, dimensión existencial del ser humano!

Por otro lado, he mencionado también mi actitud de humildad. Humildad porque este gesto viene de tan ilustres compañeros, cuyo trabajo ha permitido y permite hacer vida académica, construir derroteros de mejoramiento, socializar y difundir el conocimiento, de conformidad con los Principios y Propósitos de la Universidad. En efecto, en lo pertinente a esta actividad, el artículo 1, y el artículo 4, inciso d), rezan, respectivamente:

\footnotetext{
Artículo 1. La Universidad de Costa Rica es una institución de educación superior y cultura [...], dedicada a la enseñanza, la investigación, la acción social, el estudio, la meditación, la creación artística y la difusión del conocimiento.

Artículo 4, inciso d) Respeto a la diversidad de etnias y culturas: Reconocer el carácter pluriétnico y multicultural de la sociedad costarricense, fomentando el respeto a la diversidad de las tradiciones culturales, modos de vida y patrimonio histórico cultural.
} 
Humildad, además, porque ante esta copiosa semana en que se despliega un arcoiris de textos, entretextos y contextos lingüísticos, literarios y musicales magistralmente construidos y

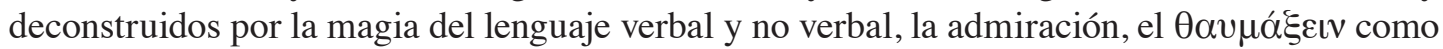
principio del conocer, me lleva a cribar los alcances de los zurcos académicos trazados a lo largo de mi vida universitaria.

Y humildad porque, a pesar de mi esfuerzo y nítida voluntad, en mucho no he logrado responder a mis maestros de aquella universidad: D. Abelardo Bonilla, D. Roberto Murillo, D. Claudio Gutiérrez, D. Arturo Agüero, D. Víctor Arroyo, D. Jézer González, D. Nicolás Farray, Dña. Clara Cornelli, D. Jack Wilson, D. Isaac Felipe Azofeina, Dña. María Eugenia Dengo, entre muchos otros.

Y, como he dicho, también me embarga el júbilo. Júbilo porque la celebración de la Semana de la Diversidad Lingüística se está constituyendo en una actividad académica consolidada, cuyo objetivo es compartir el deslinde de cruces y entrecruces de la palabra como materia prima de las producciones culturales de nuestra Costa Rica, unida en su diversidad, para construir una universidad con pertinencia.

Júbilo porque la Escuela de Filología, mediante la gestión del Departamento de Lingüística, se catapulta en la acción configuradora de una universidad que concibe el conocimiento como un bien social para escudriñar identidades, así, en plural, en pro de la promoción de la cultura no solo como erudición sino como experiencia de vida.

Júbilo porque tanto en la docencia como en mis actividades de investigación siempre tuve un trasfondo orientador: el eje lengua-cultura e identidad de nuestra Costa Rica, tanto a lo interno como en otros espacios universitarios en que compartí textos académicos gestados desde la triada docencia, investigación y extensión universitarias, fruto de experiencias compartidas con mis estudiantes, mis tesiarios y mis colegas del equipo de Lexicografía. Ante estas actividades, si bien di algunos pasos, no otra cosa me embarga sino un profundo regocijo por la oportunidad de crecer en compañía de tan generosos amigos.

Muchas gracias.

\section{Bibliografía}

Coşeriu, E. (1977). "El lenguaje y la comprensión de la existencia del hombre actual”. En: El hombre y su lenguaje. Madrid: Gredos. 
